\title{
Nanostructure and oxidation properties investigation of engine using Jatropha biodiesel as engine fuel
}

\author{
Mohd Aznan Abdul Latif ${ }^{1, *}$, Ahmad Anas Yusof ${ }^{1}$, Ahmad Zaki Shukor ${ }^{2}$, Farah Aqilah \\ Habidi $^{1}$, Nur Fathiah Mohd Nor ${ }^{1}$, Mohd Zaid Akop ${ }^{1}$, Mohd Hafidzal mohd Hanafi ${ }^{1}$, and \\ Aiman Roslizar ${ }^{1}$ \\ ${ }^{1}$ Faculty of Mechanical Engineering, Universiti Teknikal Malaysia Melaka, \\ Hang Tuah Jaya, 76100 Durian Tunggal, Melaka, Malaysia \\ ${ }^{2}$ Faculty of Electrical Engineering, Universiti Teknikal Malaysia Melaka, \\ Hang Tuah Jaya, 76100 Durian Tunggal, Melaka, Malaysia
}

\begin{abstract}
The purpose of this study is to investigate the soot nanostructure characteristic and soot oxidation behaviour that is emitted from a single cylinder diesel engine by using two different engine fuels that is Jatropha Biodiesel (JBD) with the presence of 3\% of methanol as additive and Diesel fuel. In order to obtain the result for soot characteristic, Scanning Electron Microscope (SEM) is used, while Thermogravimetric Analysis (TGA) is used to analyze the oxidation of the soot itself. The parameter for the engine testing has been fixed by applying different loads of $25 \%$ and $50 \%$ load with constant speed of $2500 \mathrm{rpm}$. The result has been compared for each fuel in terms of their structure and oxidation behaviour. The soot was collected on a filter paper and the SEM grid from the exhaust stream within the time period set. The soot is then observed by using SEM and the result shows that diesel soot particulate matter is smaller with average size of $95 \mathrm{~nm}$ for $25 \%$ load and $63.5 \mathrm{~nm}$ for $50 \%$ load than those of B20, which has the average size of $122 \mathrm{~nm}$ for $25 \%$ load and $105 \mathrm{~nm}$ for $50 \%$. It complies with the evidence that stated $11 \%$ of the oxygen content helps in lowering particulate emission by improving the combustion. The result also shows that the oxidation behaviour of B20 occurs faster than diesel either at $25 \%$ load or $50 \%$ load.
\end{abstract}

\section{Introduction}

Fuel is a basic need for vehicle to move around and its categories are three which is solid fuels, liquid fuels and gaseous fuel. As for diesel engine, biodiesel has become a good alternative fuel [1]. Generally, biodiesel and diesel are both in liquid fuels and as known, biodiesel is better than diesel. In order to reduce emission problems that cause from combustion engine, biodiesel is proposed as the solution [2]. This is because; biodiesel significantly reduces carbon emissions and other harmful particulate matter especially in producing the soot when engine is running. There is a lot of new technology that makes the engine become more powerful but less harmless to the environment [3]. As known, biodiesel is made from vegetable oil or animal fats and can be used as fuel for vehicle and

\footnotetext{
* Corresponding author: golden3744@yahoo.com
} 
diesel engine either in their pure form or mixed with mineral diesel but it is usually used as diesel additive in order to reduce level of gas emission or soot, carbon-monoxide and hydrocarbons or called as renewable resources.

The increasing population and high demand in the use of vehicles with the transformation of climate may affect the environment, creates global warming and affect human health in Malaysia. With the rising of demand for vehicle, the collection of fuel that is non-toxic for environment, less emissions, as well as less soot is now being considered. In 1990, "Rudolf Diesel" has first demonstrate the use of biodiesel in diesel engine by using peanut oil at the world exhibition that was held in Paris [4].

Diesel in engine exhaust nowadays produces black soot where it consists of carbon compounds that were not combusted and this makes the soot chemically/biologically highly active and hazardous. In order to reduce it, biodiesel fuel is used where it is a green fuel which is non-toxic biodegradable and also reduces engine emissions. As for the soot characteristic, diesel soot is formally formed by short exposure times to high temperatures and has bigger soot size than biodiesel fuel.

The main purpose to use biodiesel as an alternative fuel is to reduce emission by taking into account their nanostructure characteristic and the oxidation behaviour. Biodiesel is a renewable source and it creates less pollution than diesel. Unlike other alternative sources which often need new equipment or modification, by using biodiesel, no expensive modifications are required to the engine, and a lot easier to integrate biodiesel into current system. Table 1 shows the comparison between commercial diesel and biodiesel [5].

Table 1. Comparison between diesel and biodiesel.

\begin{tabular}{|c|c|c|}
\hline \multirow{2}{*}{ Fuel Property } & Diesel & Biodiesel \\
\cline { 2 - 3 } & ASTM D975 & ASTM D6751 \\
\hline Lower Heating Value, BTU/gal & 129,050 & 118,170 \\
\hline Kinematic Viscosity @ $40^{\circ}$ C., cSt & $1.3-4.1$ & $4.0-6.0$ \\
\hline Specific Gravity @ $60^{\circ}$ C., g/cm ${ }^{3}$ & 0.85 & 0.88 \\
\hline Carbon, wt \% & 87 & 77 \\
\hline Hydrogen, wt \% & 13 & 123 \\
\hline Oxygen, by dif. Wt \% & 0 & 11 \\
\hline Sulfur, ppm & 500 & 0 \\
\hline Boiling Point, ${ }^{\circ} \mathrm{C}$ & 180 to 340 & 315 to 350 \\
\hline Flash Point, ${ }^{\circ} \mathrm{C}$ & 60 to 80 & 100 to 170 \\
\hline Cloud Point, ${ }^{\circ} \mathrm{C}$ & $\sim 15$ to 5 & $\sim 3$ to 12 \\
\hline Pour Point, ${ }^{\circ} \mathrm{C}$ & $\sim 35$ to $\sim 15$ & $\sim 15$ to 10 \\
\hline Cetane Number & $40-50$ & $48-65$ \\
\hline Lubricity (HFRR), $\mu \mathrm{m}$ & $300-600$ & $<300$ \\
\hline
\end{tabular}

Biodiesel is a liquid that is eco friendly. It has a low processing temperature and lower oxidation stability. This is why biodiesel is accepted by the community. [6]. Different from diesel fuel and pollutants from diesel engine, it affected environment and human health such as lung cancer. From the previous study, by using biodiesel like Jatropha plant, it could reduce global warming and provide a clean air. Jatropha oil can be produce worldwide because of its potential [7]. Oil can be produced up to $40 \%$ from its seeds and 
also the properties of the oil is better compared to soybean oil and palm oil [8]. Table 2 shows that Jatropha biodiesel is considered as good as diesel.

Table 2. Properties of Jatropha biodiesel versus diesel.

\begin{tabular}{|c|c|c|}
\hline Parameters & Jatropha bio-diesel & Diesel oil \\
\hline Specific Gravity @ $15^{0} \mathrm{C}$ & $0.860-0.933$ & $0.82-0.86$ \\
\hline Sulphur & 0.13 & 1.2 \\
\hline Viscosity $(\mathrm{cST})$ & $37.00-54.80$ at $30{ }^{\circ} \mathrm{C}$ & $37.00-54.80$ at $30{ }^{\circ} \mathrm{C}$ \\
\hline Pour Point, ${ }^{0} \mathrm{C}$ & -3 & 33 to -15 \\
\hline Cloud Point, ${ }^{\circ} \mathrm{C}$ & 2 & 15 to -5 \\
\hline Flash Point, ${ }^{\circ} \mathrm{C}$ & $210-240$ & $60-80$ \\
\hline Cetane Number & $38-51$ & $40-55$ \\
\hline Heating Value $(\mathrm{Mj} / \mathrm{kg})$ & $37.83-42.05$ & 42 \\
\cline { 1 - 3 } & &
\end{tabular}

In order to make the comparison for the nanostructure characteristics and oxidative behaviour of the soot from biodiesel and diesel fuel, an experiment is carried out to analyze the characteristic and oxidative behaviour of the soot by using Jatropha biodiesel and diesel as engine fuel. For this experiment, a new pipeline will be designed and fabricated where filter paper and SEM grid will be located at the centre of the pipeline to take samples of the soot. Then, the soot sample will be analysed and compared between diesel and Jatropha biodiesel fuel for the nanostructure and oxidative reaction of the soot by using thermogravimetric analysis (TGA) and scanning electron microscopy (SEM). The objective of this research is to determine the oxidative behavior of soot using Jatropha biodiesel as engine fuel with the presence of methanol as fuel additives. Other than that, the objective is also to investigate of the nanostructure characteristics of soot emitted from a single cylinder diesel engine and also to compare the nanostructure of soot produced by two different fuels that is emitted from Jatropha biodiesel and diesel.

\section{Experimental setup}

\subsection{Design of experiment}

The apparatus, specifications of the apparatus, procedure of the experiment, design pipe from exhaust engine and flowchart of the experiment is described in this section. The apparatus that is used is a single-diesel engine for producing soot, Scanning Electron Microscope (SEM) to investigate the nanostructure characteristics.During oxidation, the structural change can be revealed using electron microscopy[9]. Thermogravimetric Analysis (TGA)is being used to investigate the oxidation behaviour of soot that is created by two different test fuels that is Jatropha biodiesel with presence of 3\% methanol and diesel. This experiment will be run at constant speed (2500rpm) with different load $(25 \%$ and $50 \%$ ) form hydraulic system that attached to the engine. Thus, for each different load for both different fuels, the nanostructure characteristic and oxidation behaviour will be investigated, analysed and compared. The main apparatus is the single-cylinder diesel engine which is use to produce emission and collect the soot sample. The specification or the parameters of the engine is shown in Table 3. 
Table 3. Engine Specifications/Parameter of KIPOR model.

\begin{tabular}{|c|c|}
\hline Content & Details \\
\hline Model & KM186FB \\
\hline Type & Vertical cooling load with water, 4 cycles \\
\hline Combustion System & Direct Injection \\
\hline No. Of Cylinder & 1 \\
\hline Bore x Stroke & $0.857(0.226)$ \\
\hline Shift & $14.0 / 2400(10.3)$ \\
\hline Rated Output & $16.0 / 2400(11.8)$ \\
\hline Rated Output as per 1 hr hp/rpm (kW) & 19.6 \\
\hline Compression Ratio & Diesel \\
\hline Fuel & BTDC 17.0 \\
\hline Injection Time & $200(2845)$ \\
\hline Injection Pressure (kg/cm2,psi) & $14.3(3.78)$ \\
\hline Fuel Tank Capacity (1) & $3.0(3.78)$ \\
\hline Lubrication System & $3.0(0.79)$ \\
\hline Lub Oil Capacity & Water-Radiator \\
\hline Cooling system & $3.0(0.79)$ \\
\hline Water Cooling Capacity &
\end{tabular}

The scanning electron microscope (SEM) is a scientific equipment which uses a beam of high- energetic electrons to generate a variety of signals in order to examine an object at the surface of solid specimens on very small fine scales. Because of the signals, it could reveal several of information about the sample such as; external morphology (texture), crystalline structure and their chemical composite/element. SEM have magnification ranging from $20 \mathrm{x}$ to approximately $30,000 \mathrm{x}$, spatial resolution of $50-100 \mathrm{~nm}$ and also analyses selected point locations on the sample which the technique is useful to identify or determine chemical composition (using EDS), crystalline structure and crystal orientation. Thus, by using SEM, it is able to analyze at high level that have been specified at nanolevel and used to measure nano particles size of the soot for this experiment.

Thermogravimetric Analysis (TGA) is a technique or method of thermal analysis which changes in physical or chemical properties of materials upon temperature with constant heating rate or upon time with constant temperature and/or constant mass loss. For measurement, TGA used to determine the composition of materials or chemical and predict their thermal stability at temperature up to $1000^{\circ} \mathrm{C}$. This kind of technique can characterize materials or chemical that exhibit weight loss or gain due to decomposition, oxidation or dehydration. The samples weights for TGA are range from $1 \mathrm{mg}$ to $150 \mathrm{mg}$ but sample weights of more than $25 \mathrm{mg}$ are preferred. For best result, sample weight of $1 \mathrm{mg}$ is enough. This sample can be analyzed in form of powder or small pieces so the interior sample temperature remains close to the measured gas temperature. For this experiment, TGA is used to predict the thermal stability at certain temperature due to oxidation behaviour of the soot from different kind of load (low to high load) at constant speed.

\subsection{Experimental procedure}

Before conducting the experiment to determine the soot oxidation and soot nanostructure of both fuels, the mixture of the Jatropha biodiesel with diesel is needed. The mixture of the fuel is B20. $25 \mathrm{ml}$ of Jahropa methyl-ester and $475 \mathrm{ml}$ of diesel fuel is mixed and stirred until it reaches homogenous consistency. The procedure on how to analyze the soot sample were basically refered to the SEM standard procedure [10]. 


\section{Results and discussion}

For the nanostructure characteristic and oxidation behaviour, the result will be discussed based on the result from the SEM image and TGA graph which had been obtained from Scanning Electron Microscopy (SEM) and Thermogravimetric Analysis (TGA). The result is compared based on the different test fuels which Diesel (D2) and Jatropha Biodiesel (B20). Besides that, the differences of the result obtained also been compared with the differences of the load given during the experiment. For the soot sample, the soot particle are in fuel spray cores formed which it obtained from the exhaust pipe that has been attached to the single cylinder engine exhaust that operate in constant speed of $2500 \mathrm{rpm}$ with $25 \%$ and 50\% load. For about 15-30 minutes, the emitted diesel and biodiesel soot particle were trapped at the filter paper and SEM grid that attached inside the pipe at the exhaust.

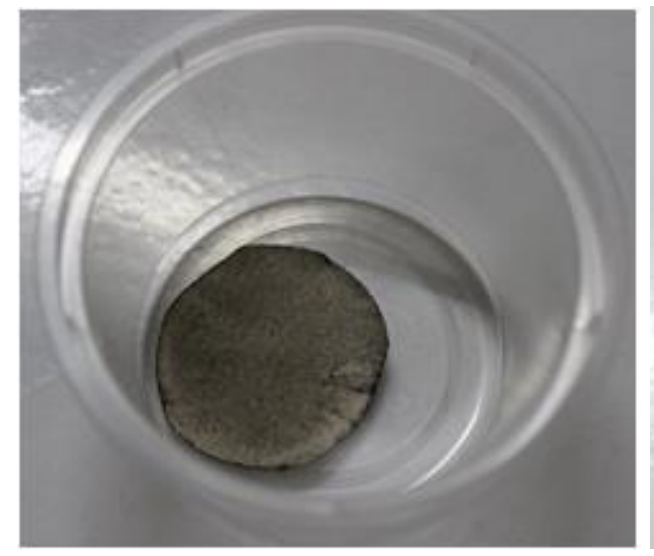

(a)

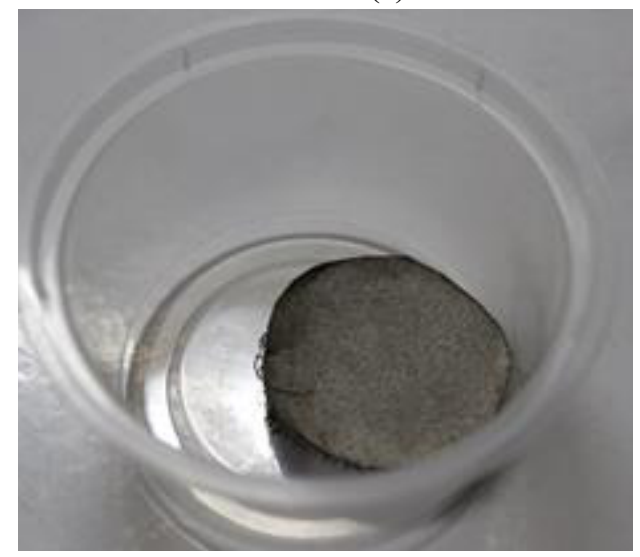

(c)

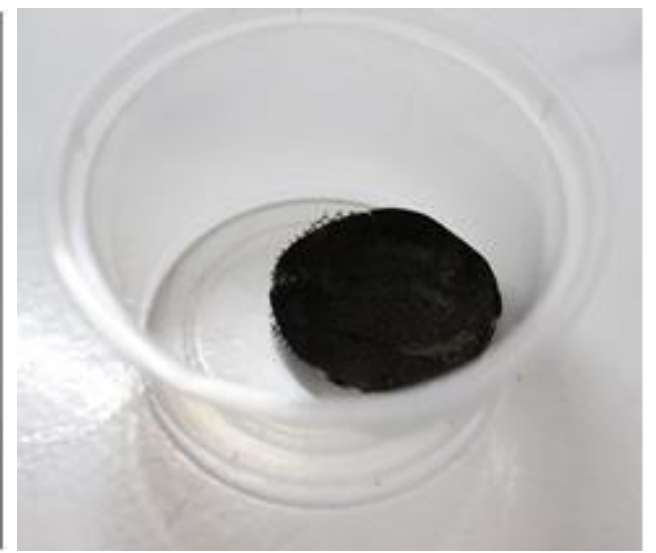

(b)

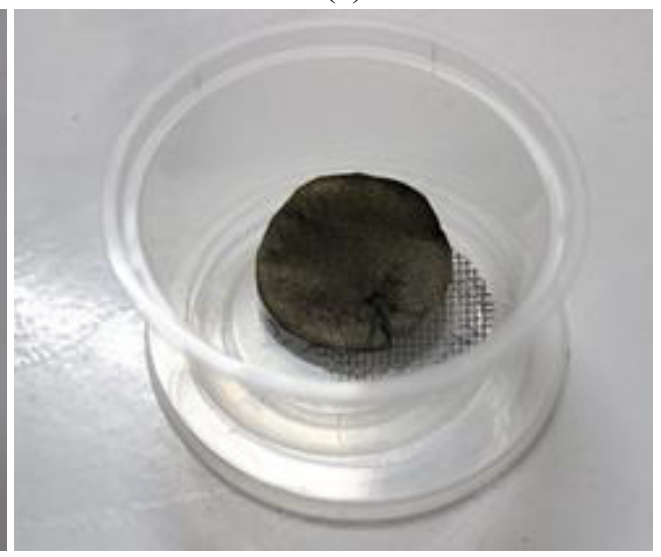

(d)

Fig. 1. (a) Filter paper of trapped fine particle of Diesel (a) $25 \%$ load, (b) $50 \%$ load and Jatropha biodiesel (B20) (c) 25\% load, (d) 50\% load with trapping duration for 30 minutes each.

As in Figure 1, all the sub-figures show the particulate concentration of soot on filter papers. The result were reported as the particle that is emitted from diesel combustion were more than Jatropha biodiesel (B20) combustion because both have same duration of trapping that is 30 minutes and particle concentration of Jatropha biodiesel are slightly lower than diesel as shown in Figure 1. By referring to the particle concentration, it can be 
observed that soot particle in diesel combustion are higher than soot particulate in Jatropha biodiesel combustion and it can be observed clearly due to the increasing load for both fuel. Due to Jatropha biodiesel is made from vegetation plant, the oil contain oxygen within the molecule fuel which it is readily been oxidized with the available oxygen in the flame zone. Besides at 25\% engine load, flaky particulates soot were collected as in Figure 1 on the left for image (a) diesel and (b) B20. At 50\% engine load, particle collection is much darker to observed at the filter papers which significantly presents a higher emissions at higher engine loads.

\subsection{Soot nanostructure characteristic using SEM}

By using scanning electron microscope (SEM), sample preparation of the soot nanostructure characteristics can be elaborated and analyzed for both Diesel (D2) and Jatropha Biodiesel (B20) fuel. The particle diameter can be visualize using SEM method [11]. Figure 2 shows the image of the soot nanostructure for Diesel (D2) fuel and Jatropha Biodiesel (B20) fuel for load of $25 \%$ with constant speed $2500 \mathrm{rpm}$.

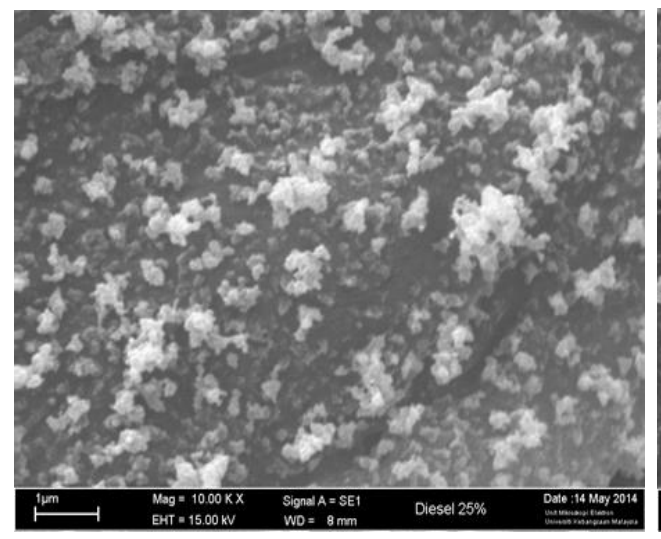

(a)

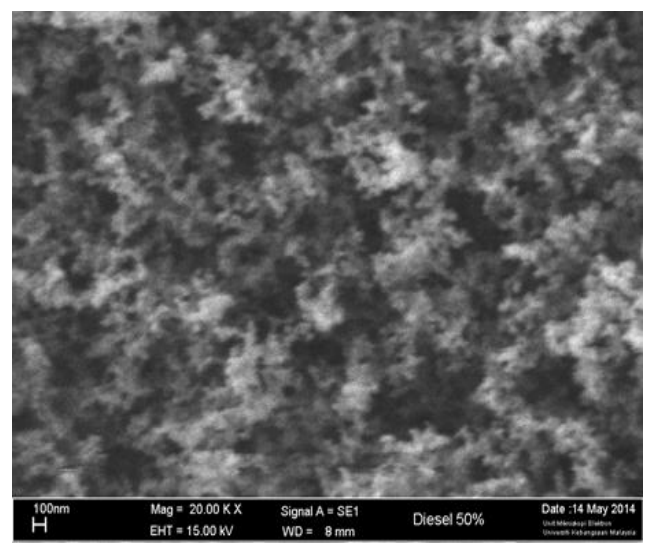

(c)

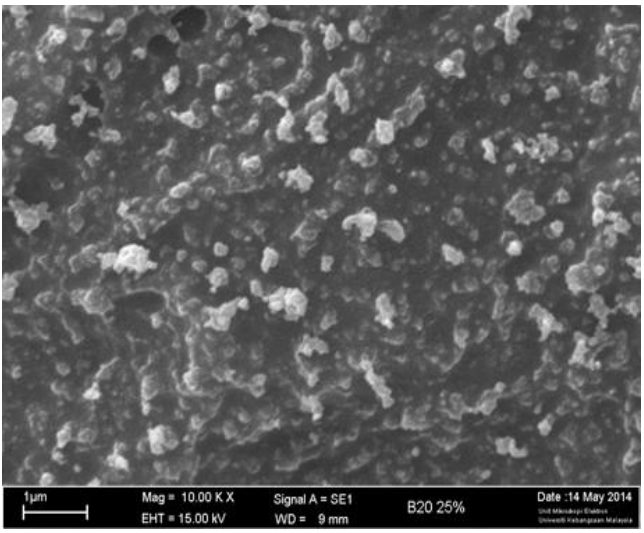

(b)

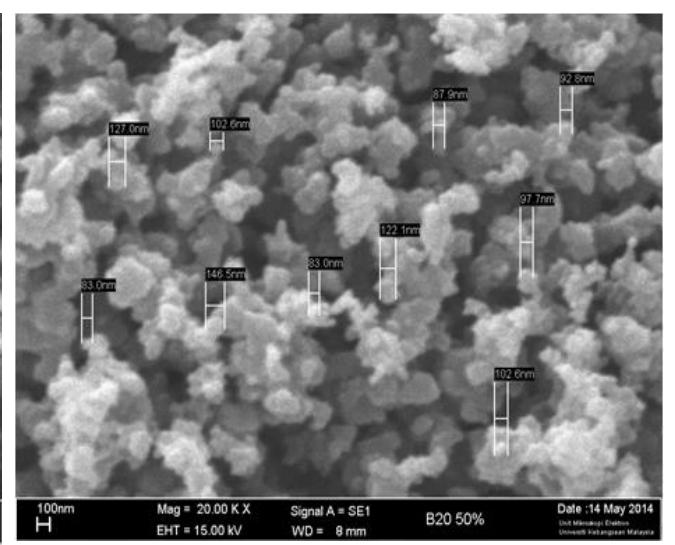

(d)

Fig. 2. Soot nanostructure at $25 \%$ load of (a) Diesel, (b) Jatropha Biodiesel (B20) and soot nanostructure at $50 \%$ load of (c) Diesel, (d) Jatropha Biodiesel (B20).

Based on Figure 2, the morphology features of both soot were analyzed and presented where the surface of morphology of the diesel soot (a) and (c) is seen to be non-uniform 
either at $25 \%$ or $50 \%$ load and the diesel soot particles are slightly small than Jatropha biodiesel soot particles.In Figure 2, the image shows the micro-image of diesel and Jatropha biodiesel particulates by SEM which in fine ranges particle. In this experiment, the average size of the soot particle for Jatropha biodiesel is $122 \mathrm{~nm}$ for $25 \%$ load and $105 \mathrm{~nm}$ for $50 \%$. As for soot particles size for diesel obtained are approximately about $95 \mathrm{~nm}$ for $25 \%$ load and $63.5 \mathrm{~nm}$ for $50 \%$ load. In this experiment, the particle image of soot is taken in order to verify and identify the particle size by micro- and nano- image. The image showed that diesel particle sizes are slightly smaller than of Jatropha biodiesel particle. The Jatropha biodiesel particulate size is approximately $80-160 \mathrm{~nm}$ whereas the diesel size is around $40-120 \mathrm{~nm}$. Besides, at higher engine load, ultrafine particle are obtained which mainly composed of organic carbon (OC), where at higher engine loads, these particle are overall covered of elemental carbon (EC). Based from previous study, the particulate mass emission can be reduce on operating condition by using biodiesel blend and also give a better engine performance compared to diesel [12]. Biodiesel fuel have a higher oxygen content in it which help in lowering particulate emission by improving the combustion [13]. Besides that, with presence of $3 \%$ additive of methanol inside B20, it also improves biodiesel performance by reducing particulates, $\mathrm{NO}_{\mathrm{x}}$, fuel dilution and carbon dioxide.

\subsection{Oxidation behaviour using TGA}

There is method can be used to determine particulate reactivity that is quantified by the temperature and oxidation rate [14]. By using thermogravimetric analysis (TGA), sample preparation of the soot oxidation behaviour can be analyze for both Diesel (D2) and Jatropha Biodiesel (B20) fuel. Figure 3 (a), (b), (c) and (d) below, show the graph of soot oxidation and the thermal behaviour of both diesel and B20 fuel for load of $25 \%$ and $50 \%$ with constant speed of $2500 \mathrm{rpm}$.

These samples were examined under the following experimental conditions:

$\begin{array}{ll}\text { Instrument } & \text { : TGA Q } 500 \\ \text { Heating Rate } & : 10 \mathrm{~K} / \mathrm{min} \\ \text { Temperature range } & : 25^{\circ} \mathrm{C} \text { to } 750^{\circ} \mathrm{C} \\ \text { Atmosphere } & : \text { Nitrogen, } 50 \mathrm{ml} / \mathrm{min}\end{array}$

As in Figure 3, the test condition for all cases start from $25^{\circ} \mathrm{C}$ to $750^{\circ} \mathrm{C}$ with nitrogen and from $50^{\circ} \mathrm{C}$ to $300^{\circ} \mathrm{C}$ is considered as evaporation moisture. Then, from $320^{\circ} \mathrm{C}$ to $400^{\circ} \mathrm{C}$ a significant major mass loss occurred with about above $80 \%$ and this is assumed to be due to hydrocarbon and carbon oxidation desorption. Finally, at above $400^{\circ} \mathrm{C}$ shows that biodiesel has more ashes than diesel which may conclude that, the oxidation rate of biodiesel is faster than diesel. The weight loss curves which are plotted in Figure 3 shows that soot from B20 starts to oxidize at slightly higher temperature than soot from diesel. Furthermore, soot from B20 oxidizes significantly at $390^{\circ} \mathrm{C}$ to $750^{\circ} \mathrm{C}$ while Diesel soot experiences weight loss at temperature of $400^{\circ} \mathrm{C}$ and above. therefore, it can be concluded that Diesel produces soot that is less reactive than soot from B20. 


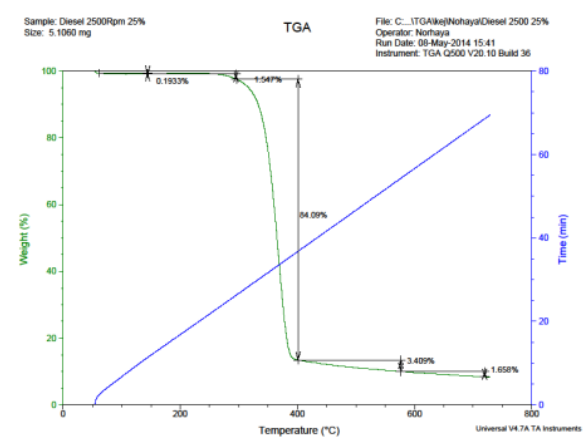

(a)

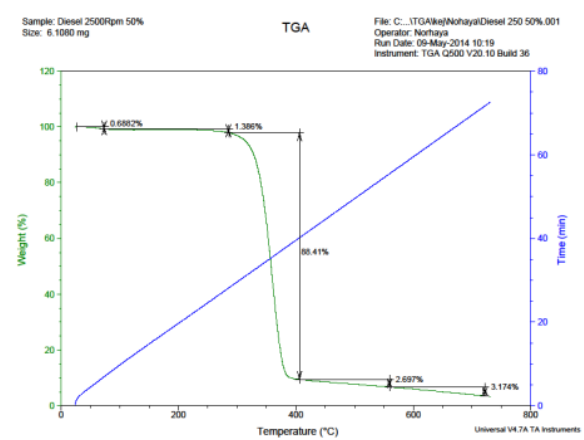

(c)

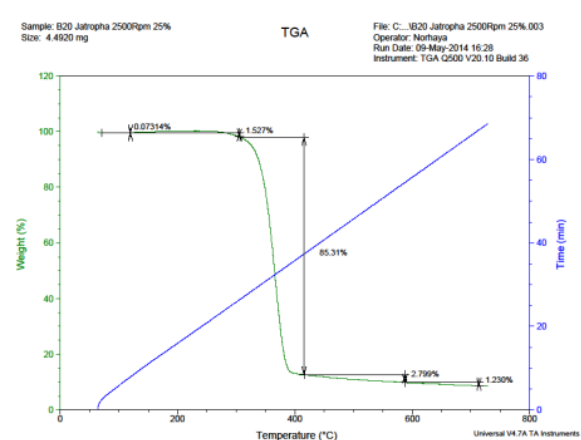

(b)

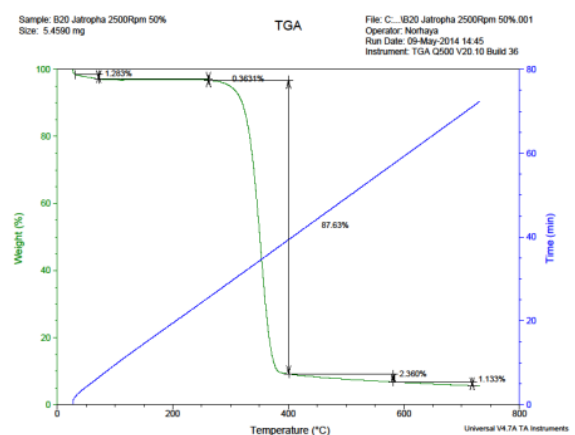

(d)

Fig. 3. Comparison of TGA curve and conversion of (a) diesel 25\% load, (b) B20 25\% load, (c) diesel $50 \%$ load and (d) B20 50\% load with constant speed $2500 \mathrm{rpm}$ for all cases.

\section{Conclusions}

Equations As a conclusion, it can be said that the objectives of the experiment has been achieved. The investigation and comparison of soot nanostructure characteristic of soot emitted from single cylinder diesel engine of diesel and B20 is successfully determined by using SEM. The result shows that, the soot nanostructure for diesel and B20 at two different loads where diesel soot particulate matter are smaller with average size of $95 \mathrm{~nm}$ for $25 \%$ load and $63.5 \mathrm{~nm}$ for $50 \%$ load than B20 with average size of $122 \mathrm{~nm}$ for $25 \%$ load and $105 \mathrm{~nm}$ for $50 \%$. The surface of morphology of diesel soot is seen to be non-uniform and chain-like agglomerations than B20.

For the oxidation behaviour of soot, there are three possibilities for the oxidation behaviour reactions that are, at higher engine load, it produces higher in-cylinder temperature which leads to faster oxidation reaction. Secondly, oxidation behaviour could react when the sample is in low particle size and have high surface area and a last possibility is because of the presence of oxygen in the biodiesel. Besides that the presence of methanol as an additive improves the performance of biodiesel by reducing the particulates thus could also help on the oxidation behaviour in B20.

Through out this experiment, there were several limitations that becomes an obstacle to get a more in-depth result for both sample in order to obtain better results. First, the limitation that had been faced is the engine load. Due to the condition of the engine itself, the engine that can be imposed is below $75 \%$. This is because, the engine uses a hydraulic 
system, if the load exceeds $75 \%$, it will cause the engine to wear out faster than their long term life cyle.

Second is the cost limitation. In order to get an exact and detail image of the soot nanostructure, Transmission Electron Microscopy (TEM) were suggested, where by using TEM, details result of soot nanostructure can be observed and obtained for example their soot morphology, chemical compositions and crystalline structure. But, due to cost limitation, the analysis of soot nanostructure can only afforded by using Scanning Electron Microscope (SEM). Same goes for Thermogravimetric Analysis (TGA) where, it only can observe and determine the oxidation behaviour. To analyze deeper on the oxidation behaviour, the differential scanning calorimetry (DSC) can be used to investigate the thermal characteristic which is the thermal critical points like melting points, enthalpy heat temperature or substance, but it requires a higher cost.

As for recommendation, this experiment should provide with various types of fuel sample in the future. There should be at least three samples of fuel blended Jatropha Biodiesel (JBD) that is B15, B20 and B100 which then can be compared with conventional diesel. This is because; there will be more variable result that can be obtained during the experiment. The fuel test sample should also include fuel blended without the addition of $5 \%$ methanol as additives so that the results can differentiate between conventional diesel and blended fuel with presence of additives.

Another recommendation is to do an Energy dispersive spectroscopy (EDS) to analyse deeper on soot nanostructure or soot morphology and determining their chemical compositions and crystalline structure. For oxidation behaviour, the differential scanning calorimetry (DSC) can be used to investigate the thermal characteristic that is the thermal critical points like melting points, enthalpy heat temperature or substance.

The authors wish to acknowledge Ministry of Education, Malaysia (KPM) through research grant RAGS/2013/FKM/TK01/02/B00041 for supporting and funding these research activities. The authors also thanks to Universiti Teknikal Malaysia Melaka (UTeM) and Green \& Energy Efficient Technology Research Group (GrEET) under Center for Advance Research on Energy (CARE) for the facilities provided.

\section{References}

1. P. Tan, Z. Hu, D. Lou, and Z. Li, Exhaust emissions from a light-duty diesel engine with Jatropha biodiesel fuel, Energy, 39, no. 1, pp. 356-362, (2012)

2. M. Happonen, T. Lähde, M. E. Messing, T. Sarjovaara, M. Larmi, L. R. Wallenberg, A. Virtanen, and J. Keskinen, The comparison of particle oxidation and surface structure of diesel soot particles between fossil fuel and novel renewable diesel fuel, Fuel, 89, no. 12, pp. 4008-4013, (2010)

3. M. Balat, H. Balat, C. Öz, Progress in bioethanol processing, ScienceDirect, 34, pp. 551-573, (2008)

4. P. K. Sahoo and L. M. Das, Combustion analysis of Jatropha, Karanja and Polanga based biodiesel as fuel in a diesel engine, Fuel, 88, no. 6, pp. 994-999, (2009)

5. M Herskowitz, M. Landau, I. Reizner and kaliya, Production of diesel fuel from vegetable and animal oils. U.S. Patent 20060207166 A1, Sep. 21, (2006)

6. S. Jain and M. P. Sharma, Oxidation and thermal behavior of Jatropha curcas biodiesel influenced by antioxidants and metal contaminants, International Journal of Engineering, Science and Technology, 3, no. 4, pp. 65-75, (2011)

7. A. B. Chhetri, M. S. Tango, S. M. Budge, K. C. Watts and M. R. Islam, Non-Edible Plant Oils as New Sources for Biodiesel Production, International Journal of Molecular Science, pp. 169-180, (2008) 
8. V. C. Pandey, K. Singh, J. S. Singh, A. Kumar, B. Singh, and R. P. Singh, Jatropha curcas: A potential biofuel plant for sustainable environmental development, Renewable Sustainable Energy Reviews, 16, no. 5, pp. 2870-2883, (2012)

9. R. L. V. Wal, A. Yezerets, N. W. Currier, D. H. Kim, and C. M. Wang, HRTEM Study of diesel soot collected from diesel particulate filters, Sciencedirect, 45, pp. 70-77, (2007)

10. D. Kim and C. M. Feng. SEM Standard operating procedure. Internet http://www.sci.ccny.cuny.edu, [June 14,2016]

11. Y. Songsaengchan, C. Chareonphonphanich, P. Karin, N. Chollacoop, M. Tongroon, and K. Hanamura, Physical Characterization of Biodiesel Particulate Matter by SEM, The Second TSME International Conference on Mechanical Engineering, (2011)

12. J. N. Gangwar, T. Gupta, and A. K. Agarwal, Composition and comparative toxicity of particulate matter emitted from a diesel and biodiesel fuelled CRDI engine, Atmospheric Environment, 46, pp. 472-481, January, (2012)

13. H. Jung, D. B. Kittelson and M. R. Zachariah, Characteristics of SME BiodieselFueled Diesel Particle Emissions and the Kinetics of Oxidation, Environmental Science and Technology, 40, pp. 4949-4955, (2006)

14. J. Song, M. Alam, A. L. Boehman, and U. Kim, Examination of the oxidation behavior of biodiesel soot, sciencedirect, 146, pp. 589-604, (2006) 